\title{
The Research on Uighur by Means of Electropalatograph
}

\author{
Kaili Binu \\ Key Lab of China's National \\ Linguistic Information Technology, \\ Northwest University for \\ Nationalities \\ KLCNLIT,NUN \\ LanZhou, China \\ e-mail: 377942403@qq.com
}

\author{
Yanhua Duan \\ Key Lab of China's National \\ Linguistic Information Technology, \\ Northwest University for \\ Nationalities \\ KLCNLIT,NUN \\ LanZhou, China \\ e-mail: 446549989@qq.com
}

\author{
Yanhua Mei \\ College of Foreign Languages of \\ Northwest University for \\ Nationalities \\ CFLNUN \\ LanZhou, China \\ e-mail: 377942403@qq.com
}

\begin{abstract}
This paper aims at analyzing the conarticulation in Uyghur VC syllable by means of Electropalatograph (EPG). The economy principle in speech production can be easy to trace by means of EPG. The tongue characteristics of the same consonant after different kinds of vowels are different from each other. This research reproves that vowels usually affect the posterior consonants in syllables by slightly changing theirs original articulation places, sometimes even changing their articulation manners.
\end{abstract}

Keywords- Electropalatograph; Uighur; VC syllable; Coarticulation

\section{INTRODUCTION}

Linguists have analyzed articulation places and manners of different consonants on the basis of traditional linguistics for many years, especially auditory recognition, resulting that a great number of theories have been founded. However, some of those founded theories are very abstract without convincing proves. Besides the description of articulation places and manners, traditional linguists have also explained coarticulations in a simply way. Then a new subject, called experimental linguistics, emerged, which aims at convincingly explaining a series of phonetic phenomenon. With widely-using techniques and new research approach, the tide of experimental linguistics has brought a lot of new views towards traditional linguistics. In this paper, a useful research tool called electropalatal will be introduced to deepen your understanding towards coarticulation in Uighur.

\section{EPG AND ITS ARTIFICIAL PALATAL}

EPG is a kind of artificial palatal used by researchers to analyze the speech production process of consonants. Researchers usually choose some speech producers, and attach artificial palatal to their palatal. Then let speech producers to read vowels, consonants, syllable, word, phrases, even sentence. During speech production, the artificial palatal will transmit the tongue-palatal contact information to the computer. Most of all, those acquired contact information can be analyzed and can be used to rebuild the psychological speech production. The following is the structure of EPG artificial palatal.

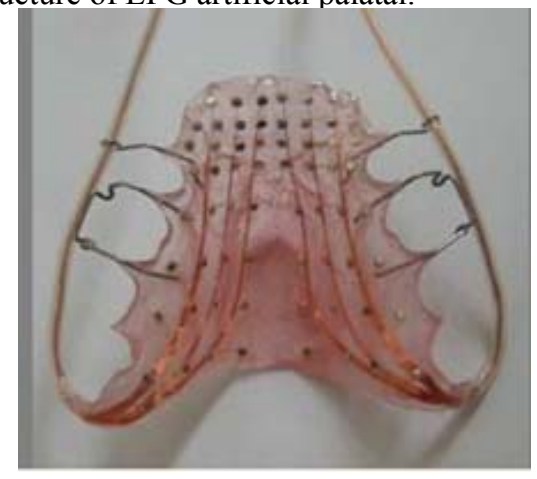

Figure 1. TOtAl CONTACT OF Uighur AfFricAtes.

From fig.1, it is can be observed that EPG artificial palatal is embedded with sixty two electrodes, which can acquire the contact information when tongue contacts the electrodes in the artificial palatal. All the sixty two electrodes will judge whether the tongue organ contacts them or not. Then a matrix included contact tongue-palatal information will be formed and stored as a single file.

\section{EXPERIMENTAL PROGRAM}

\section{A. Word list design}

$/ \mathrm{a} /, \mathrm{i} /, \mathrm{u} / \mathrm{are}$ the most special articulated vowels, for which /a/ is with the widest openness, /i/ is with the narrowest openness, and $/ \mathrm{u} /$ is with the most posterity. Then those three vowels are chosen to collocate with consonants in Uyghur. Table 1 is all the consonants that can be located after $/ \mathrm{a} /, / \mathrm{i} /, / \mathrm{u} /$. 
TABLE I. COLLOCATION BETWEEN VOWELS /A/, /I/,/U/ AND CONSONANTS

\begin{tabular}{|c|l|l|l|l|l|l|l|l|l|l|l|l|l|}
\hline vowels consonants & $\mathrm{t}$ & $\mathrm{l}$ & $\mathrm{s}$ & $\mathrm{z}$ & $\mathrm{J}$ & $\mathrm{q}$ & $\mathrm{h}$ & $\mathrm{j}$ & $\mathrm{t}$ & $\mathrm{j}$ & $\mathrm{b}$ & $\mathrm{r}$ & $\mathrm{N}$ \\
\hline $\mathrm{a}$ & at & al & as & az & a & aq & ah & aj & $/$ & aq & ab & $/$ & $/$ \\
\hline i & it & il & is & iz & if & $/$ & $/$ & $/$ & it & $/$ & $/$ & $/$ & $/$ \\
\hline u & ut & ul & us & uz & $/$ & uq & uh & uj & ut & $/$ & $/$ & ur & un \\
\hline
\end{tabular}

From table 1, it can be concluded that not all the consonants can be located after /a/, /i/, /u/ at the same time; there are only four consonants can do that: $/ \mathrm{t} /, / 1 /, / \mathrm{s} /, / \mathrm{z} /$, among which, $/ \mathrm{z} /$ is the only voiced consonant and the others are voiceless consonants. Then, this paper will magnify the tiny differences among syllables with same vowel or same voiceless consonant by analyzing the colocation between vowels $/ \mathrm{a} /, / \mathrm{i} /, / \mathrm{u} /$ and consonants $/ \mathrm{t} /, / 1 /, / \mathrm{s} /$.

\section{B. Signals acquisition and processing}

Two speech producers, a young male and a young female are chosen to read our designed syllables in this experimental.And two speech producers are native Uyghur without speech production illness. EPG signals are recorded by Palatometer 6300 , setting $100 \mathrm{~Hz}$ as EPG sampling rate and $16000 \mathrm{~Hz}$ as audio sampling rate.

After signal acquisition, all EPG and audio signals are processed by Matlab Program. The processing includes signal cutting and parameters compute. Signal cutting bases on the principle of choosing the most stable onset frame of
EPG matrix as the representative of a consonant in a certain syllable. After signal cutting, the computing of chosen key matrixes is also practiced by Matlab to obtain some scientific parameters. And those parameters consist of two domains: contacted electrodes area percentage parameters and distribution parameters. In order to compare and analyze, all those parameters will be presented in percentage.

\section{COARTICUlAtion In UighuR VC Syllable}

\section{A. Effect of vowel on consonant /t/}

Table 2 demonstrates the cut key matrixes of consonant /t/ in different syllables, however, all these syllables ends with the same consonant $/ \mathrm{t} /$, but begins with $/ \mathrm{a} /, \mathrm{i} / \mathrm{l}$ or $/ \mathrm{u} /$. From those matrixes, it can be observed clearly that there seems no obvious differences between male and female when they produce the same syllable. But there do exist vital differences among different syllables.

TABLE II. EPG OF CONSONANTS /T/ IN DIFFERENT SYLLABLES

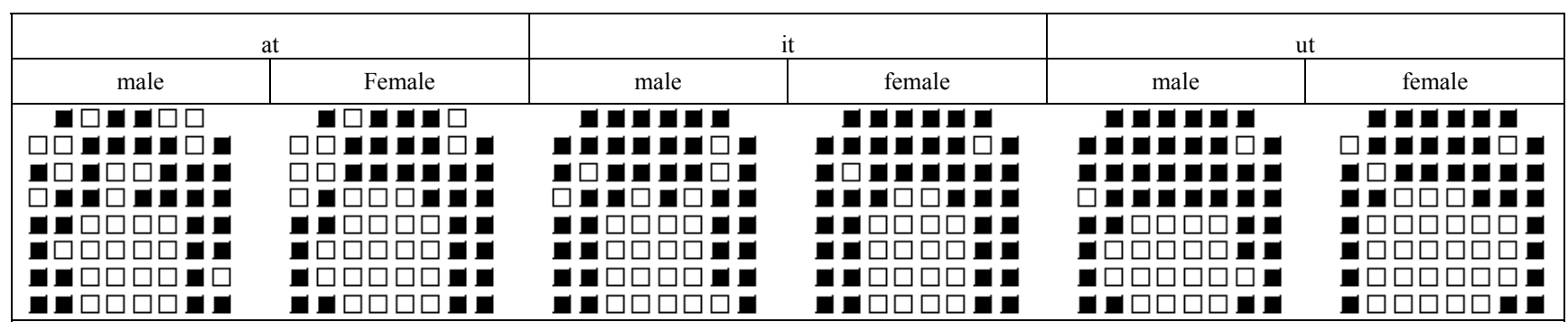

Among those matrixes, both /at/ matrixes is without full contact in the first two ranks, however, /it/ and /ut/ matrixes are nearly full contact in the first two rank. To make the

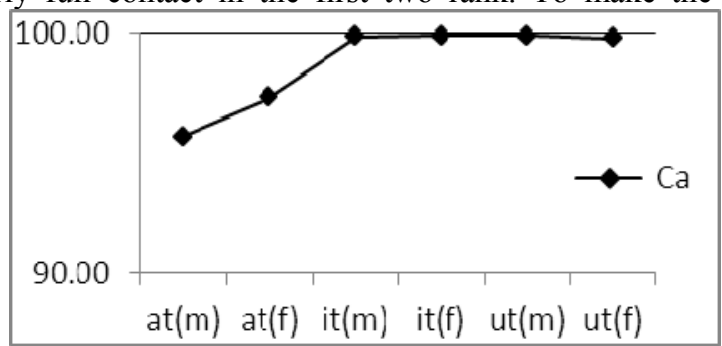

comparison more vividly and scientifically, just move our focus on Fig.2..

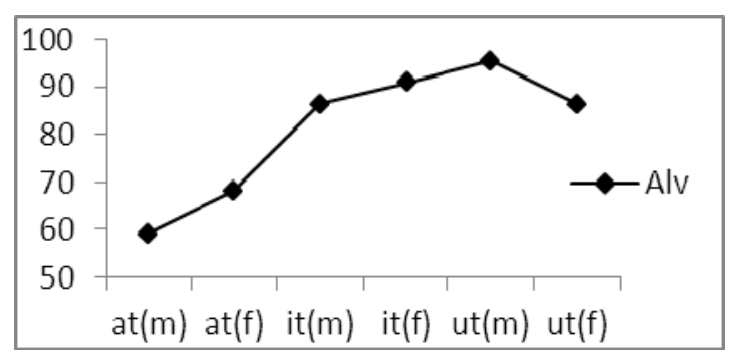

Figure 2. Contact Anteriority and Alveolar Distribution Percentage for Consonant /T/.

In Fig.2, (m) means syllable pronounced by male, and (f) by female. It presents the tongue-palatal contact anteriority and alveolar distribution, which mainly includes the first three ranks of the matrix. Parameter $\mathrm{Ca}$ in syllable /at/ is relatively lower than that in syllables /it/ and /ut/. What's more, Parameter Alv is much more obvious in in their 
differences: $\mathrm{Ca}$ of $/ \mathrm{t} / \mathrm{in} / \mathrm{at} / \mathrm{is}$ much less than that in /it/ and /ut/. And this can be concluded: when producing /at/, speech producers don't constrain their tongue tip as strongly as producing /it/ and /ut/.

\section{B. Effect of vowel on consonant /s/}

Table 3 demonstrates the key matrixes of consonant $/ \mathrm{s} /$ in different syllable ended with the same consonant $/ \mathrm{t} /$. From those matrixes, male and female producers also indicate the speech production consistency in same syllable. But there do exist vital differences among different syllables. The biggest difference is velar contact among them.

TABLE III. EPG OF CONSONANTS /S/ IN DIFFERENT SYLLABLES

\begin{tabular}{|c|c|c|c|c|c|}
\hline \multicolumn{2}{|c|}{ as } & \multicolumn{2}{|c|}{ is } & \multicolumn{2}{|c|}{ us } \\
\hline male & Female & male & female & male & female \\
\hline 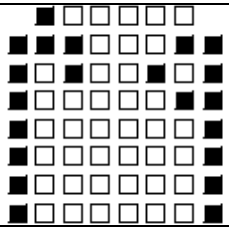 & 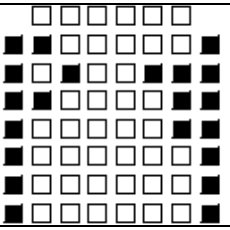 & 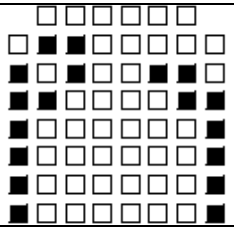 & 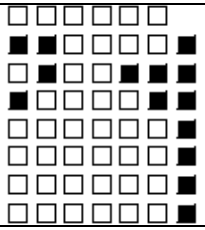 & 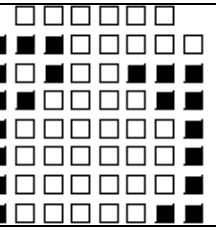 & 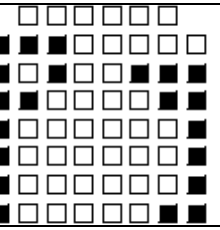 \\
\hline
\end{tabular}

Fig. 3 demonstrates velar distribution percentage for consonant $/ 1 /$, where the velar percentage of /us/ is higher than the others. That's because the tongue-palatal contact of /us/ is more in the last rank / than that of /as/ and /is/. In the last rank of the key matrixes, there exists more contact on its right in /us/, two electrodes, however, there only one contacted electrode on the right of the last rank in /as/ and /us/.

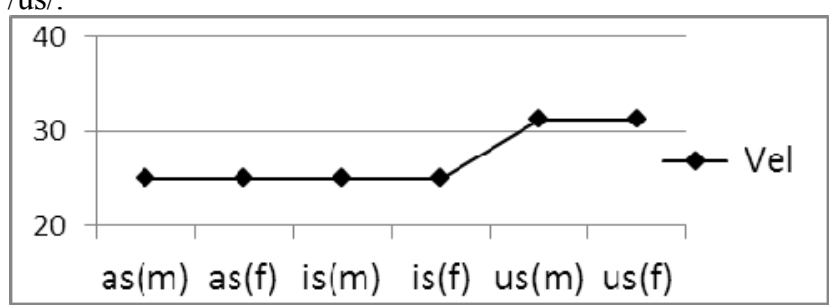

\section{Effect of vowel on consonant /l/}

Table 4 demonstrates the key matrixes of consonant $/ 1 /$ in different syllable ended with the same consonant $/ t /$. There seems exists no speech production difference in gender, but exist obvious differences among different syllables. Both sides of the last four ranks electrodes are contacted in syllable /il/ while it is a totally different situation in syllables /al/ and /ul/. However, the contact mode in syllables /al/ and $/ \mathrm{ul} /$ are almost the same.

Figure 3. Veolar distribution percentage for consonant /1/.

TABLE IV. EPG OF CONSONANTS /L/ IN DIFFERENT SYLLABLES

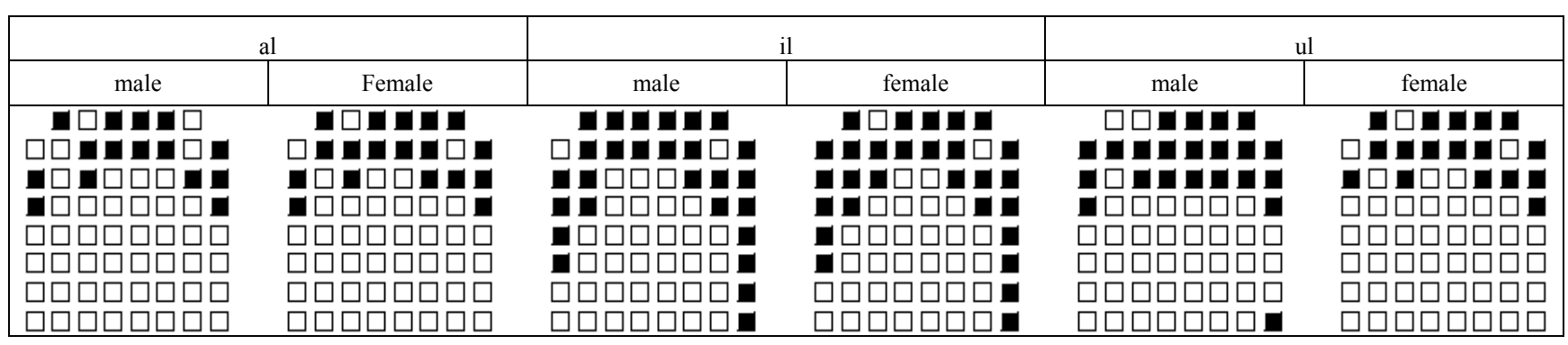

To make the date more valid and convincible, the above key matrixes are computed, then the computed data is presented in Fig. 4, which demonstrate the post palatal distribution percentage for consonant $/ 1 /$. It is can be observed apparently that consonant in syllable /il/ is with much higher post palatal distribution.

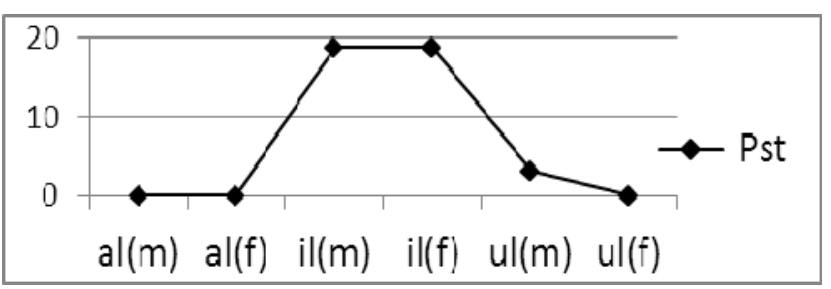

Figure 4. POST Palatal Distribution PERCENTAGE FOR CONSONANT /L/ 


\section{SUMMARY}

In Uyghur, the voiceless consonant would convey some articulation places and manners information of its anterior vowels within syllables. Then different vowel situations lead to that the tongue characteristics of the same consonant after different kinds of vowels are different from each other by slightly changing theirs original articulation places to coarticulated with their anterior vowels, sometimes even changing their articulation manners. However, the degree of this kind of affection hasn't analyzed, which will be investigated in future research.

\section{ACKNOWLEDGEMENT}

This research was financially supported by the postdoctoral project of Northwest University for Nationalities.

\section{REFERENCES}

[1] MorganBarry RA.EPG from square one: An overview of electropalatography as an aid to therapy, Clinic Linguistics and Phonetics, 1989,3(1):81-91

[2] Farnetani, E.(1997). Coarticulation and connected speech processes. In Hardcastle, W. J.\& Laver, J. (eds.) The Handbook of Phonetc Sciences, 371-404. Oxford: Blackwell pub-lisher.

[3] Liu Jia. Articulation place of consonants in standard Chinese: research based on EPG. Zhejiang Univeristy, 2006.

[4] Li Yonghong, The Research on Tibetan Consonants in Xiahe Dialect by Means of Electropalatograph, The 2nd International Conference on Multimedia Technology,Vol.6, 2011,7. 